\title{
Potential role of gabapentin and extended- release gabapentin in the management of menopausal hot flashes
}

This article was published in the following Dove Press journal:

International Journal of General Medicine

6 August 2013

Number of times this article has been viewed

\section{Manisha Yadav \\ Judith Volkar}

Center for Specialized Women's Health, Cleveland Clinic Foundation, Cleveland, Ohio, USA
Correspondence: Manisha Yadav Palo Alto Medical Foundation, 2734 El Camino Real, Santa Clara, CA-9505I, USA

$\mathrm{Tel}+$ I 40843 I 4708

Fax + I 4085245733

Email yadav.manisha@gmail.com

\begin{abstract}
About $80 \%$ of postmenopausal women experience vasomotor symptoms, such as hot flashes and night sweats - symptoms that are associated with sleep disruption and can lead to fatigue and mood changes. Moreover, hot flashes can be embarrassing for women, causing difficulties at work and in their social lives. Many therapies have been advocated for relief of vasomotor symptoms, but only hormone therapy has been US Food and Drug Administration approved. However, after the Women's Health Initiative Study suggested that there was a correlation between hormone therapy and increased risk for breast cancer and cardiovascular events, many women stopped taking hormone therapy, and many do not want to initiate it. Hormone therapy is also contraindicated in certain women, such as those with a history of hormone-stimulated cancer like breast and uterine cancer. Gabapentin (Neurontin) has shown efficacy in relieving vasomotor symptoms and is used as off-label for this indication. A new extended-release formulation of gabapentin has also shown efficacy in treating hot flashes and improving sleep quality with possibly fewer side effects than regular gabapentin.
\end{abstract}

Keywords: Hot flushes, vasomotor symptoms, postmenopausal, hormone-sensitive cancer, non-hormonal therapy, gastric-retentive, Breeze

\section{Introduction}

Approximately $80 \%$ of postmenopausal women experience vasomotor symptoms, such as hot flashes and night sweats. ${ }^{1-5}$ A hot flash or hot flush is a discrete episode of intense heat that starts at the chest and travels upward toward the neck and face, causing facial flushing. It can last for several seconds to several minutes and can be followed by sweating and heart palpitations. ${ }^{1,6,7}$ This can happen several times during the day and night, disrupting a woman's sleep and leading to fatigue and irritability. $3,8,9$

Hormone therapy is the only US Food and Drug Administration (FDA)-approved therapy for vasomotor symptoms ${ }^{6}$ and has been shown to be cost-effective. ${ }^{3}$ However, in 2002, a report based on the Women's Health Initiative Study suggested that hormone therapy was associated with an increased risk of breast cancer and cardiovascular events, prompting many women to stop taking it. In addition, not all patients are candidates for hormone therapy. For women with a history of hormone-stimulated cancer like breast cancer ${ }^{8,10}$ and uterine cancer, ${ }^{10}$ and those with a history of thromboembolic diseases, such as venous thrombosis, ${ }^{11}$ clotting factor defects, active liver disease, and stroke, hormone therapy is contraindicated. Certain other comorbidities, such as smoking ${ }^{11}$ and uncontrolled hypertension, make a woman a less-than-ideal candidate for hormone therapy; the risks may outweigh the benefits. Finally, some women, for personal reasons, would prefer to avoid hormone therapy. For such special populations, 
alternative therapy is necessary to achieve a safe and effective way to relieve vasomotor symptoms.

Many studies have shown the efficacy of a variety of nonhormonal prescription medicines, but none have yet been FDA approved. Clinicians have been using gabapentin off-label to help relieve hot flashes in postmenopausal women. A new extended-release formulation of gabapentin has also shown efficacy in treating hot flashes and improving sleep quality with potentially fewer side effects than regular gabapentin. ${ }^{12-18}$

This article will review efficacy of gabapentin in reducing hot flashes and the potential role of extended-release gabapentin in providing similar benefits with potentially fewer side effects.

\section{Menopause and vasomotor symptoms}

There are many postulated theories regarding the cause of vasomotor symptoms. The most common one involves the role of declining or fluctuating estrogen levels and its effect on the hypothalamus - the center of temperature regulation. It is thought that there are estrogen receptors in the hypothalamus, and when estrogen levels fall or fluctuate, the thermoneutral center in the hypothalamus narrows. Neurotransmitters serotonin and norepinephrine have been found to affect the temperature regulation center of the hypothalamus as well. ${ }^{19-23}$ In addition, core temperature increases in postmenopausal women. ${ }^{22}$

The goal of treating a woman's hot flashes is to improve her quality of life. ${ }^{3}$ Various scales have been constructed and validated to measure quality of life during the peri- and postmenopausal periods. The Utian Quality of Life questionnaire, for example, assesses four domains of life: occupational, health, emotional, and sexual. ${ }^{24}$ Other various questionnaires are used to measure menopause-related symptoms, such as the Kupperman index, ${ }^{25}$ the Greene Climacteric Scale, ${ }^{26,27}$ and those by Ware and Sherbourne ${ }^{28}$ and Hunter. ${ }^{29}$

\section{Gabapentin}

Gabapentin was initially developed to control seizures. Due to its nerve-stabilizing properties, it was later found to be an effective treatment for neuropathic pain (eg, postherpetic neuralgia, diabetic neuropathy, and pain caused by spinal cord injury). It has also been shown to have some efficacy for migraine prophylaxis, essential tremor, bipolar disorder, uremic pruritus, and fibromyalgia. ${ }^{7,9,30}$ In postmenopausal women with vasomotor symptoms, gabapentin improved sleep quality. ${ }^{9,31}$ Although selective serotonin reuptake inhibitors (SSRI), selective norepinephrine reuptake inhibitors
(SNRI), and clonidine ${ }^{32}$ are also helpful, the benefit of gabapentin is its safety profile. It has no drug interactions; no absolute contraindications (some rare risk of increased suicidal risk, hypersensitivity), ${ }^{33}$ and a quick onset of action. It is excreted by the kidneys as an unchanged drug. ${ }^{7,34-36}$ The half-life of gabapentin is about 5-7 hours, and its clearance depends on creatinine clearance (ie, kidney function).

The effect of gabapentin on hot flashes has been wellstudied, but the exact mechanism of action is not known. Gabapentin binds to $\alpha 2 \delta$ subunit of voltage-gated calcium channels, which are present in the central nervous system and peripherally. ${ }^{37}$

More specifically, it is thought that the ventromedial part of the hypothalamus may be the specific target of gabapentin, because this area has a high concentration of voltage-gated calcium channels and substance $\mathrm{P}$ projections. ${ }^{38}$ The high amount of substance $\mathrm{P}$ projections in the hypothalamus may stimulate the hypothalamic cooling center, which plays a role in vasomotor symptoms. ${ }^{39}$

\section{Efficacy}

Many randomized placebo-controlled studies demonstrate that gabapentin is effective in treating vasomotor symptoms. A randomized, double-blinded, placebo-controlled, multiinstitutional study was conducted by Pandya et $\mathrm{al}^{7}$ to evaluate the efficacy of gabapentin in controlling hot flashes (two or more a day) in 420 women with breast cancer. They were randomly divided into three groups: placebo; gabapentin $300 \mathrm{mg} /$ day; and gabapentin $900 \mathrm{mg}$ /day. The drugs were given in three divided doses daily for 8 weeks. A self-reported diary was maintained by the patients in which they documented the frequency, severity, and duration of hot flashes for 1 week before and 8 weeks after the start of the study drugs. Data was available for 371 patients at week 4 and for 347 patients at week 8 .

The results demonstrated that in the gabapentin $300 \mathrm{mg}$ group, the reduction in the hot flash severity score was 33\% and $31 \%$ at week 4 and 8 , respectively. The reduction in the hot flash severity score in the gabapentin $900 \mathrm{mg}$ group was $49 \%$ and $46 \%$ at week 4 and 8 , respectively. The placebo group also experienced a reduction in the hot flash severity score ( $21 \%$ and $15 \%$ at week 4 and 8 , respectively), reflecting a placebo effect. The side effects experienced by patient population were somnolence and fatigue.

A randomized, double-blinded, placebo-controlled trial by Butt et $\mathrm{al}^{6}$ compared the efficacy and tolerability of gabapentin against placebo for controlling hot flashes in postmenopausal women who had entered menopause naturally. 
The trial was conducted from March 2004 to April 2006 in the greater Toronto area in community and primary care offices. The 197 women between the ages of 45-65 who participated had at least 14 hot flashes weekly. They were randomized to two groups: The study group received gabapentin $300 \mathrm{mg}$ three times a day; and the control group received placebo three times a day, for a total of 4 weeks. A decrease of 51\% in the hot flash score was noted in the active arm as compared to $26 \%$ in the placebo group $(P<0.001)$. The side effect profile was similar to the study by Pandya et $\mathrm{al}^{7}$ mentioned earlier. Other symptoms experienced were dizziness, unsteadiness, and drowsiness.

Loprinzi et $\mathrm{al}^{40}$ performed a prospective, Phase III, double-blind, placebo-controlled clinical trial in 214 men with hot flashes who were on an androgen-deprivation therapy program for prostate cancer. There were four study groups: placebo; gabapentin, $300 \mathrm{mg}$ /day; gabapentin, $600 \mathrm{mg} /$ day; and gabapentin, $900 \mathrm{mg} /$ day. Hot flash frequency and severity were recorded daily for 1 week before the start of the study and for 4 weeks after the study drugs were started. The mean hot flash scores declined in all four groups: by 4.1 units in the placebo group; 3.2 units in the gabapentin $300 \mathrm{mg}$ group; 4.6 units in the gabapentin $600 \mathrm{mg}$ group; and 7 units in the gabapentin $900 \mathrm{mg}$ group.

\section{Comparison with other treatments}

A Cochrane Review published in $2010^{8}$ showed that gabapentin, SSRIs, SNRIs, clonidine, and relaxation therapy had mild-to-moderate effects on reducing vasomotor symptoms. The study reviewed six randomized trials that assessed the efficacy of nonhormonal therapies for relief of hot flashes in women who were unable to take hormonal therapy due to breast cancer. The trials also included data on homeopathy, vitamin E, magnetic devices, and acupuncture. None of these had better efficacy than placebo in relieving hot flashes.

A randomized, double-blinded, placebo-controlled trial by Reddy et $\mathrm{al}^{41}$ compared the efficacy of estrogen and gabapentin to placebo in reducing hot flash severity and frequency. Gabapentin and estrogen had a similar efficacy ( $71 \%$ and $72 \%$, respectively) in reducing the hot flush composite score, which accounts for both hot flush severity and frequency. The placebo arm showed an efficacy of 54\%. The study was conducted for 12 weeks. The dose of estrogen was $0.625 \mathrm{mg} / \mathrm{day}$, and the gabapentin group received a dose of $2,400 \mathrm{mg} /$ day.

Loprinzi et $\mathrm{al}^{42}$ performed an individual patientpooled analysis, taking data from seven clinical trials of antidepressant medications, namely paroxetine, venlafaxine, fluoxetine, and sertraline, and comparing their efficacy to placebo in reducing hot flash scores. This study also included three trials of gabapentin compared with placebo. The analysis showed a reduction in hot flash scores of: $41 \%$ for paroxetine; $33 \%$ for venlafaxine; $13 \%$ for fluoxetine; and $3 \%-18 \%$ for sertraline, when compared with placebo. Gabapentin reduced the hot flash score in $35 \%-38 \%$ of the women compared with placebo.

Both gabapentin and venlafaxine showed similar efficacy in reducing hot flash scores in another study. ${ }^{43}$

Gabapentin was more effective at reducing hot flash frequency and the hot flash score than vitamin $\mathrm{E}$ in breast cancer survivors (57\% and $67 \%$ versus $10 \%$ and $7 \%$, respectively; $P<0.05)$. Gabapentin improved sleep quality as assessed by the Pittsburgh Sleep Quality Index score in the same population by $21.33 \% .^{9}$

In women with hormone-positive breast cancer, gabapentin is a better choice for controlling vasomotor symptoms than SSRI, because it does not interact with tamoxifen, unlike paroxetine, fluoxetine, sertraline, and citalopram. ${ }^{7}$ Both sertraline and citalopram are weaker inhibitors of CYP2D6 than paroxetine or fluoxetine. ${ }^{44}$

\section{Use with other treatments}

Loprinzi also conducted a 5-week randomized trial consisting of 118 women with hot flashes that were inadequately controlled by antidepressant therapy (either a monoamine oxidase inhibitor or a tricyclic antidepressant). ${ }^{45}$ The women were randomly assigned to one of two groups: One received both an antidepressant and gabapentin, and the other was weaned off the antidepressant and began taking gabapentin alone. There was no statistical difference between the two arms in terms of hot flash reduction. ${ }^{45}$

\section{Safety and patient acceptability}

The randomized trial by Butt et $\mathrm{al}^{6}$ studying gabapentin showed that the most common side effects initially experienced by patients were dizziness (18\%), unsteadiness (14\%), and drowsiness (12\%). Other studies showed a similar sideeffect profile. ${ }^{7,9,41}$ However, these side effects had largely resolved by week 4 of treatment.

A study looking at hot flashes in men reported a compliance rate of $>96 \%$ in patients taking gabapentin $900 \mathrm{mg}$ daily; there were no significant side effects. ${ }^{40}$ A study by Butt et $\mathrm{al}^{6}$ showed similar compliance rates between gabapentin and placebo groups. The latter study consisted of women who had entered menopause naturally. 
Table I Change in average daily frequency of moderate or severe hot flashes from baseline after 4 weeks of treatment relative to placebo

\begin{tabular}{lll}
\hline Doses & BREEZE I & BREEZE 2 \\
\hline $\mathrm{I}, 200 \mathrm{mg}$ & $-0.96 \pm 0.38$ & $-\mathrm{I} .6 \mathrm{I} \pm 0.53$ \\
& $(P=0.0 \mathrm{II})$ & $(P=0.0024)$ \\
$\mathrm{I}, 800 \mathrm{mg}$ & $-1.5 \mathrm{I} \pm 0.38$ & $-1.5 \mathrm{I} \pm 0.52$ \\
& $(P=<0.000 \mathrm{I})$ & $(P=0.0040)$ \\
\hline
\end{tabular}

The effective starting dose of gabapentin when used for treatment of hot flashes is $900 \mathrm{mg} / \mathrm{day} ;{ }^{7,9}$ lower doses are not recommended. ${ }^{40}$

\section{Role of extended-release gabapentin}

The gabapentin extended-release (ER) tablet swells when it comes in contact with gastric secretions and - due to its increased size - is not passed through the pyloric sphincter and, hence, becomes gastric retentive. ${ }^{46}$ The drug is slowly released over about 10 hours to the upper intestine and absorbed systemically. ${ }^{47}$ Gabapentin ER has been shown to have the similar bioavailability as gabapentin immediaterelease (IR) ${ }^{48}$ Interestingly, it has been noted that the bioavailability of gabapentin IR decreases with increasing dose, but not so much for the ER gabapentin. ${ }^{48,49}$ This is due to saturable absorption mechanism in its primary site of absorption - the small intestine..$^{50}$

The slow release of gabapentin ER over prolonged time may mitigate the saturation of the receptors in the small intestine, ${ }^{51}$ and hence lead to better bioavailability, especially at higher doses, when compared to gabapentin IR. Gabapentin ER takes longer to reach the peak concentration; the maximum concentration is lower with a longer plateau phase, compared to the immediate release formulation. ${ }^{49}$ Gabapentin ER should be taken with food, as the fed status increases the retention of the gabapentin ER in the stomach. ${ }^{52,53}$ Under fasting status, the time to reach maximum plasma concentration $\left(\mathrm{t}_{\text {max }}\right)$ for both formulations is similar due to the similar transit time, but the maximum concentration reached for gabapentin ER decreases

Table 2 Change in average daily frequency of moderate or severe hot flashes from baseline after 12 weeks of treatment relative to placebo

\begin{tabular}{lll}
\hline Doses & BREEZE I & BREEZE 2 \\
\hline $\mathrm{I}, 200 \mathrm{mg}$ & $-0.56 \pm 0.42$ & $-1.56 \pm 0.5 \mathrm{I}$ \\
& $(P=0.1830)$ & $(P=0.0024)$ \\
$\mathrm{I}, 800 \mathrm{mg}$ & $-1.53 \pm 0.4 \mathrm{I}$ & $-1.12 \pm 0.5 \mathrm{I}$ \\
& $(P=0.1975)$ & $(P=0.028 \mathrm{I})$ \\
\hline
\end{tabular}

Table 3 Change in average daily severity score of moderate or severe hot flashes from baseline after 4 weeks of treatment relative to placebo

\begin{tabular}{lll}
\hline Doses & BREEZE I & BREEZE 2 \\
\hline $\mathrm{I}, 200 \mathrm{mg}$ & $-0.26 \pm 0.08$ & $-1.15 \pm 0.08$ \\
& $(P=0.0016)$ & $(P=0.0608)$ \\
$\mathrm{I}, 800 \mathrm{mg}$ & $-0.32 \pm 0.08$ & $-1.28 \pm 0.08$ \\
& $(P<0.000 \mathrm{I})$ & $(P=0.0003)$ \\
\hline
\end{tabular}

significantly as the drug is minimally released..$^{49}$ Furthermore, the fat content of the meal also influences the time to reach maximum concentration for gabapentin ER. The $t_{\max }$ increases with the increasing fat content of the meal, and slightly better bioavailability was noted for gabapentin ER. ${ }^{49}$ In spite of the above differences, the half-life and oral or renal clearance for both ER and IR gabapentin was found to be similar. ${ }^{49}$ Because of its pharmacokinetic properties, gabapentin ER can be taken less frequently, compared to the IR formulation, with maintained bioavailability and efficacy. ${ }^{49}$ It is speculated that the lower peak and longer plateau phase may decrease the side effects noted with immediate release formulation. ${ }^{49}$ Gabapentin ER has been shown to be well-tolerated in several studies. ${ }^{48,49,54}$ Most common side effects noted were dizziness, ${ }^{48,49,54,55}$ headache, ${ }^{48,49,54}$ somnolence, ${ }^{48,49,54,55}$ and peripheral edema. ${ }^{54}$ These were at most mild-to-moderate in intensity. ${ }^{48,49,54,55}$ Dizziness and somnolence were noted to be reduced when gabapentin ER was given in divided dose compared to the single dose. ${ }^{55}$

The safety and efficacy of ER gabapentin has been demonstrated in studies evaluating its effect on postherpetic neuralgia and it is FDA approved for this indication. A double-blind, randomized, placebo-controlled clinical trial conducted in 2007 by Irving et al, ${ }^{56}$ consisted of 158 patients who suffered from postherpetic neuralgia for 3 months. Their baseline average daily pain was $\geq 4$ in a scale from $0-10$. The patients were divided into three groups: the first group received gabapentin ER 1,800 $\mathrm{mg}$ daily in the evening; the second received gabapentin ER $600 \mathrm{mg}$ in the morning and 1,200 $\mathrm{mg}$ in evening; and the third received a placebo.

Table 4 Change in average daily severity score of moderate or severe hot flashes from baseline after 12 weeks of treatment relative to placebo

\begin{tabular}{lll}
\hline Doses & BREEZE I & BREEZE 2 \\
\hline $\mathrm{I}, 200 \mathrm{mg}$ & $-0.20 \pm 0.10$ & $-0.21 \pm 0.10$ \\
& $(P=0.0433)$ & $(P=0.0280)$ \\
$\mathrm{I}, 800 \mathrm{mg}$ & $-0.20 \pm 0.10$ & $-0.29 \pm 0.10$ \\
& $(P=0.0468)$ & $(P=0.0026)$ \\
\hline
\end{tabular}


Table 5 BREEZE 3 changes noted in frequency and severity score of moderate or severe hot flashes from baseline at 4 weeks and 12 weeks relative to placebo

\begin{tabular}{lll}
\hline Doses & 4 Weeks & I 2 Weeks \\
\hline Frequency & -1.69 & -1.14 \\
& $(P<0.000 I)$ & $(P=0.0007)$ \\
Severity & -0.21 & -0.19 \\
& $(P<0.000 \mathrm{I})$ & $(P=0.0040)$ \\
\hline
\end{tabular}

The study was conducted for 4 weeks. Efficacy was measured by assessing the change in average daily pain from baseline and the average daily sleep interference score. Pain scores were lowest in the group with twice-a-day dosing of gabapentin ER. There was a statistically significant reduction in average daily sleep interference scores in both gabapentin ER groups compared with the placebo group. ( $P=0.048$ and $P=0.006$ for once-daily and twice-daily regimen, respectively, versus placebo.)

In 2008 a study conducted by Jensen et $\mathrm{a}^{57}$ found similar results. Specifically, twice-a-day dosing (600 mg in morning and 1,200 $\mathrm{mg}$ in evening) was more effective at relieving sharp, dull, sensitive, and itchy postherpetic pain than a once-a-day regimen of $1,800 \mathrm{mg}$ in the evening.

Gabapentin's role in improving vasomotor symptoms was shown in the BREEZE 1,2 , and 3 trials, ${ }^{12-18}$ which looked at the efficacy of gabapentin ER (Serada ${ }^{\circledR}$; Depomed, Inc, Newark, CA, USA), an investigational drug in treating menopausal hot flashes. All three trials were prospective, Phase III, randomized, placebo-controlled, multicenter trials performed in the United States. The primary outcome was hot flash severity and frequency at 4 weeks and 12 weeks. The BREEZE 1 and BREEZE 3 trials had an additional assessment at 6 months to evaluate the persistence of gabapentin ER efficacy. The trials enrolled more than 1,700 postmenopausal women (541 in BREEZE 1; 565 in BREEZE 2; and 600 in BREEZE 3). All participants had an average of seven or more moderate-to-severe hot flashes per day or a minimum of 50 hot flashes per week, along with episodes of sweating, in the prior 30 days. They were divided into three groups: placebo; 1,200 mg gabapentin ER once daily; and 1,800 mg ER - $600 \mathrm{mg}$ in morning and 1,200 $\mathrm{mg}$ at bedtime.

Results for the BREEZE 1 trial $^{16}$ : when compared to the placebo, both $1,200 \mathrm{mg}$ and $1,800 \mathrm{mg}$ doses showed statistical significance in reduction of frequency and severity of hot flashes at 4 weeks $(P<0.0001$ to $P=0.0117)$.

BREEZE 2 trial results ${ }^{15}$ : compared to the placebo, the $1,200 \mathrm{mg}$ group showed statistically significant reduction in hot flash frequency at weeks 4 and $12(P=0.0024)$. The $1,800 \mathrm{mg}$ dose showed statistical significance in the reduction of hot flash frequency at week $4(P=0.0040)$ and reduction of hot flash severity at weeks 4 and $12(P=0.0003$ and $P=0.0026$, respectively) (Tables $1-4$ ).

Though not statistically significant, both $1,200 \mathrm{mg}$ and $1,800 \mathrm{mg}$ doses showed improvement in other primary outcomes compared to placebo in both trials $(P=0.0280$ to $P=0.1975) .{ }^{15,16,17}$

Results for BREEZE 3 trial $^{18}$ were presented at the October 2012 North American Menopause Society (NAMS) meeting (Table 5). When compared to the placebo, statistically significant reduction was noted in average frequency and severity of hot flashes at 4 weeks $(P<0.0001)$. At 12 weeks, statistically significant reduction was noted for hot flash frequency $(P=0.0007)$, but not for severity $(P=0.0102)$. Even at 24 weeks, gabapentin ER was more

Table 6 Adverse events in the BREEZE trials

\begin{tabular}{|c|c|c|c|c|c|c|}
\hline & \multicolumn{2}{|l|}{ BREEZE I } & \multicolumn{2}{|l|}{ BREEZE 2} & \multicolumn{2}{|l|}{ BREEZE 3} \\
\hline & $\begin{array}{l}\text { Treatment } \\
\text { group }\end{array}$ & $\begin{array}{l}\text { Placebo } \\
\text { group }\end{array}$ & $\begin{array}{l}\text { Treatment } \\
\text { group }\end{array}$ & $\begin{array}{l}\text { Placebo } \\
\text { group }\end{array}$ & $\begin{array}{l}\text { Treatment } \\
\text { group }\end{array}$ & $\begin{array}{l}\text { Placebo } \\
\text { group }\end{array}$ \\
\hline Nausea & $7.8 \%$ & $3.9 \%$ & $5.3 \%$ & $1.6 \%$ & & \\
\hline Dizziness & $21.4 \%$ & $2.8 \%$ & $18 \%$ & $2.7 \%$ & $13 \%$ & $3 \%$ \\
\hline Somnolence & $16.3 \%$ & $2.2 \%$ & $7.7 \%$ & $3.2 \%$ & $6 \%$ & $3 \%$ \\
\hline Headache & $9 \%$ & $5.6 \%$ & $6.1 \%$ & $7.6 \%$ & $9 \%$ & $8 \%$ \\
\hline Sedation & & & $3.4 \%$ & $0.5 \%$ & & \\
\hline Vomiting & $4.5 \%$ & $2.2 \%$ & & & & \\
\hline Fatigue & $5 \%$ & $1.6 \%$ & & & & \\
\hline Flatulence & $5 \%$ & $1.1 \%$ & & & & \\
\hline $\begin{array}{l}\text { Upper respiratory } \\
\text { tract infection }\end{array}$ & $5.9 \%$ & $5.6 \%$ & & & & \\
\hline Nasopharyngitis & $7 \%$ & $3.9 \%$ & & & & \\
\hline Weight gain & $3.9 \%$ & $2.2 \%$ & & & & \\
\hline Back pain & $2.5 \%$ & $5.0 \%$ & & & & \\
\hline
\end{tabular}


Table 7 Serious adverse events

\begin{tabular}{|c|c|c|c|c|}
\hline & \multicolumn{2}{|l|}{ BREEZE I } & \multicolumn{2}{|l|}{ BREEZE 2} \\
\hline & $\begin{array}{l}\text { Treatment } \\
\text { group }\end{array}$ & $\begin{array}{l}\text { Placebo } \\
\text { group }\end{array}$ & $\begin{array}{l}\text { Treatment } \\
\text { group }\end{array}$ & $\begin{array}{l}\text { Placebo } \\
\text { group }\end{array}$ \\
\hline $\begin{array}{l}\text { Total number } \\
\text { affected }\end{array}$ & 8 & 4 & 4 & 2 \\
\hline Chest pain & & I & I & \\
\hline $\begin{array}{l}\text { Coronary artery } \\
\text { disease }\end{array}$ & & I & & \\
\hline $\begin{array}{l}\text { Cerebrovascular } \\
\text { disorder }\end{array}$ & & I & & \\
\hline $\begin{array}{l}\text { Gastroesophageal } \\
\text { reflux disease }\end{array}$ & I & & & \\
\hline UTI & I & & & \\
\hline Breast cancer & 2 & & & \\
\hline Lung cancer & I & & & \\
\hline Ovarian cancer & & & I & \\
\hline Rib fracture & 1 & & & \\
\hline Pneumothorax & I & & & \\
\hline Abdominal hernia & & I & & \\
\hline Nerve compression & I & & & \\
\hline $\begin{array}{l}\text { Overdose attempt } \\
\text { suicide }\end{array}$ & & & I & \\
\hline Accidental overdose & & & I & \\
\hline
\end{tabular}

Abbreviation: UTI, urinary tract infection.

efficacious compared to the placebo. Significantly more women in the treatment arm said their symptoms improved versus women in the placebo arm (68\% at 12 weeks; $78 \%$ at 24 weeks versus $54 \%$ in placebo arm at 12 and 24 weeks).

The BREEZE 3 Trial also studied impact on sleep as assessed by the Insomnia Severity Index score ${ }^{58}$ and the Daily Sleep Interference Score. ${ }^{59}$ Clinically meaningful improvement was noted in both scores at 12 and 24 weeks compared to placebo. ${ }^{18}$

Common adverse effects in all three trials were similardizziness, headache, and somnolence (Tables 5 and 6). Other adverse events noted which were not very significant were: nausea, sedation, vomiting, fatigue, flatulence, upper respiratory tract infection, nasopharyngitis, weight gain, chest pain, gastroesophageal reflux disease exacerbation, breast cancer, lung cancer, ovarian cancer, rib fracture, pneumothorax, abdominal hernia, nerve compression, overdose (attempted suicide), and accidental overdose. (Tables 5 and 6.)

\section{Conclusion}

Women who suffer from hot flashes but who cannot or will not take hormone therapy can be offered nonhormonal therapies. Nonpharmacological therapies, such as acupuncture, soy, vitamin E, black cohosh, (which have not been proven to be any more efficacious than placebo), or pharmacological therapies, such as SSRI, SNRI, clonidine, or gabapentin, either IR or ER - all have demonstrated efficacy in treatment of vasomotor symptoms. Gabapentin, in both IR form and ER form, has minimal side effects.

The benefit of ER gabapentin is from the longer plateau phase, minimizing the side effect profile further than that of the immediate release formulation. Finally, patients can take the ER tablets once or twice a day, whereas regular gabapentin must be taken three times a day, allowing increased compliance.

\section{Disclosure}

The authors have no conflicts of interest to disclose.

\section{References}

1. Shen W, Stearns V. Treatment strategies for hot flushes. Expert Opin Pharmacother. 2009;10(7):1133-1144.

2. Hayes LP, Carroll DG, Kelley KW. Use of gabapentin for the management of natural or surgical menopausal hot flashes. Ann Pharmacother. 2011;45(3):388-394.

3. Elavsky S, McAuley E. Physical activity, symptoms, esteem, and life satisfaction during menopause. Maturitius. 2005;52(3-4): 374-385.

4. Santoro N. Symptoms of menopause: hot flushes. Clin Obstet Gynecol. 2008;51(3):539-548.

5. Utian WH. Psychosocial and socioeconomic burden of vasomotor symptoms in menopause: a comprehensive review. Health Qual Life Outcomes. 2005;3:47.

6. Butt DA, Lock M, Lewis JE, Ross S, Moineddin R. Gabapentin for the treatment of menopausal hot flashes: a randomized controlled trial. Menopause. 2008;15(2)2:310-318.

7. Pandya KJ, Morrow GR, Roscoe JA, et al. Gabapentin for hot flashes in 420 women with breast cancer: a randomised double-blind placebocontrolled trial. Lancet. 2005;366(9488):818-824.

8. Rada G, Capurro D, Pantoja T, et al. Non-hormonal interventions for hot flushes in women with a history of breast cancer [review]. Cochrane Database Syst Rev. 2010;9:CD004923.

9. Biglia N, Sgandurra P, Peano E, et al. Non-hormonal treatment of hot flushes in breast cancer survivors: gabapentin vs vitamin E. Climacteric. 2009;12(4):310-318.

10. North American Menopause Society. Treatment of menopause- associated vasomotor symptoms: position statement of The North American Menopause Society. Menopause. 2004;11(1):11-33.

11. Rossouw JE, Anderson GL, Prentice RL, et al. Risks and benefits of estrogen plus progestin in healthy postmenopausal women: principal results from the Women's Health Initiative randomized controlled trial. JAMA. 2002;288(3):321-333.

12. The North American Menopause Society. The Effect of Outliers on Hot Flash Frequency in the Breeze 1 Study of Gabapentin-ER for the Non-Hormonal Treatment of Vasomotor Symptoms. Philadelphia, PA, USA: The North American Menopause Society; 2010. Available from: http://journals.lww.com/menopausejournal/Citation/2010/17060/21st_ Annual_Meeting_of_The_North_American.26.aspx. Accessed January 5, 2012.

13. Effect of Gabapentin Extended Release (G-ER) on hot flashes in postmenopausal women- BREEZE 2 study, presented at NAMS Oct 2010. Baron M, Utian W, Portman D, Koltun W, Cowles V, Sathyanarayana R, Sweeney M. Available at http://phx.corporate-ir.net/External.File?item= UGFyZW50SUQ9NjU5MDB8Q2hpbGRJRD0tMXxUeXB1PTM=\& $\mathrm{t}=1$. Accessed January 5, 2012. 
14. Hyer, R. Internal Medicine News.com [homepage on the Internet]. Rockville, MD, USA: Gabapentin Extended Release Effective for Moderate to Severe Hot Flashes in Postmenopausal Women; 2010. Available from: http://www.internalmedicinenews.com/ single-view/gabapentin-extended-release-effective-for-moderate-tosevere-hot-flashes-in-postmenopausal-women/c7a8f2d553.html?tx ttnews[sViewPointer]=1. Accessed February 5, 2012.

15. ClinicalTrials.gov [homepage on the Internet]. Study of gabapentin extended release (G-ER) in the treatment of vasomotor (hot flashes/hot flushes) symptoms in postmenopausal women. US National Institutes of Health; 2008 [updated February 21, 2012; cited month/dd/yyyy]. Available from: http://clinicaltrials.gov/ct2/show/NCT00777023. Accessed February 2, 2012.

16. ClinicalTrials.gov [homepage on the Internet]. Study of gabapentin extended release (G-ER) in the treatment of vasomotor (hot flashes/hot flushes) symptoms in postmenopausal women. US National Institutes of Health; 2008 [updated February 3, 2012; cited month/dd/yyyy] Available from: http://clinicaltrials.gov/ct2/show/NCT00755417. Accessed February 2, 2012.

17. Depomed Inc. Depomed reports results from two Phase 3 clinical trials evaluating non-hormonal therapy for menopausal hot flashes [press release]. Depomed Inc., Menlo Park, CA, USA. Available from http://investor.depomedinc.com/phoenix.zhtml?c=97276\&p=irolnewsArticle\&ID=1340722\&highlight. [October 8, 2010]. Accessed February 2, 2013.

18. Depomed Inc. BREEZE 3 data for Serada ${ }^{\circledR}$ presented at 2012 North American Menopause Society Annual Meeting [press release]. Menlo Park, CA, USA: PRNewswire; 2012 [October 3]. Available from: http://www.prnewswire.com/news-releases/breeze-3-data-for-seradapresented-at-2012-north-american-menopause-society-annual-meeting-172446971.html\#13600742071654\&req=rpuCloseMe. Accessed February 20, 2013.

19. Deecher DC. Physiology of thermoregulatory dysfunction and current approaches to the treatment of vasomotor symptoms. Expert Opin Investig Drugs. 2005;14(4):435-448.

20. Kronenberg F. Hot flashes: epidemiology and physiology. Ann NY Acad Sci. 1990;592:52-86.

21. Sturdee DW. The menopausal hot flush - anything new? Maturitas. 2008;20;60(1):42-49.

22. Freedman RR, Subramanian M. Effects of symptomatic status and the menstrual cycle on hot flash-related thermoregulatory parameters. Menopause. 2005;12(2):156-159.

23. Stearns V. Clinical update: new treatments for hot flushes. Lancet. 2007;369(9579):2062-2064.

24. Utian WH, Janata JW, Kingsberg SA, Schluchter M, Hamilton JC. The Utian Quality of Life (UQOL) Scale: development and validation of an instrument to quantify quality of life through and beyond menopause. Menopause. 2002;9(6):402-410.

25. Alder E. The Blatt-Kupperman menopausal index: a critique. Maturitas 1998;29(1):19-24.

26. Greene JG. A factor analytic study of climacteric symptoms J Psychosom Res. 1976;20(5):425-430.

27. Greene JG. Constructing a standard climacteric scale. Maturitas. 1998;29(1):25-31.

28. Ware JE Jr, Sherbourne CD. The MOS 36-item short-form health survey (SF-36): I. Conceptual framework and item selection. Med Care. 1992;30(6):473-483.

29. Hunter M. The women's health questionnaire: a measure of mid-aged women's perceptions of their emotional and physical health. Psychology and Health. 1992;7(1):45-54.

30. Arnold LM, Goldenberg DL, Stanford SB, et al. Gabapentin in the treatment of fibromyalgia: a randomized, double-blind, placebocontrolled, multicenter trial. Arthritis Rheum. 2007;56(4):1336-1344

31. Yurcheshen ME, Guttuso T Jr, McDermott M, Holloway RG, Perlis M. Effects of gabapentin on sleep in menopausal women with hot flashes as measured by a Pittsburgh Sleep Quality Index factor scoring model. J Womens Health (Larchmt). 2009;18(9):1355-1360.
32. Pandya KJ, Raubertas RF, Flynn PJ, et al. Oral clonidine in postmenopausal patients with breast cancer experiencing tamoxifen-induced hot flashes: a University of Rochester Cancer Center Community Clinical Oncology Program study. Ann Intern Med. 2000;132(10):788-793.

33. US Food and Drug Administration [homepage on the Internet]. Neurontin (gabapentin) capsules, tablets, and oral solution. US Food and Drug Administration; 2009 [update August]. Available from http:// www.fda.gov/Safety/MedWatch/SafetyInformation/Safety-RelatedDrugLabelingChanges/ucm154552.htm. Accessed January 4, 2012.

34. Chadwick D. Gabapentin. Lancet. 1994;343(8889):89-91.

35. Morris GL. Gabapentin. Epilepsia. 1999; 40(Suppl 5):S63-S70.

36. Canadian Pharmacists Association. Compendium of Pharmaceuticals and Specialties: The Canadian Drug Reference for Health Professionals, 41st ed. Ottawa, Ontario: Canadian Pharmacists Association; 2006:1426-1429.

37. Gee NS, Brown JP, Dissanayake VU, Offord J, Thurlow R, Woodruff GN. The novel anticonvulsant drug, gabapentin (Neurontin), binds to the alpha2delta subunit of a calcium channel. J Biol Chem. 1996; 271(10):5768-5776

38. Yamano M, Inagaki S, Kito S, Tohyama M. A substance P-containing pathway from the hypothalamic ventromedial nucleus to the medial preoptic area of the rat: an immunohistochemical analysis. Neuroscience. 1986;18(2):395-402.

39. Rance NE, Young WS III. Hypertrophy and increased gene expression of neurons containing neurokinin-B and substance-P messenger ribonucleic acids in the hypothalami of postmenopausal women. Endocrinology. 1991;128(5):2239-2247.

40. Loprinzi CL, Dueck AC, Khoyratty BS, et al. A phase III randomized, double-blind, placebo-controlled trial of gabapentin in the management of hot flashes in men (NOOCB). Ann Oncol. 2009;20(3): $542-549$.

41. Reddy SY, Warner H, Guttuso T Jr, et al. Gabapentin, estrogen, and placebo for treating hot flushes: a randomized controlled trial. Obstet Gynecol. 2006;108(1):41-48.

42. Loprinzi CL, Sloan J, Stearns V, et al. Newer antidepressants and gabapentin for hot flashes: an individual patient pooled analysis. J Clin Oncol. 2009;27(17):2831-2837.

43. Bordeleau L, Pritchard KI, Loprinzi CL, et al. Multicenter, randomized, cross-over clinical trial of venlafaxine versus gabapentin for the management of hot flashes in breast cancer survivors. J Clin Oncol. 2010;28(35):5147-5152.

44. Jeppesen U, Gram LF, Vistisen K, Loft S, Poulsen HE, Brøsen K. Dose-dependent inhibition of CYP1A2, CYP2C19 and CYP2D6 by citalopram, fluoxetine, fluvoxamine and paroxetine. Eur J Clin Pharmacol. 1996;51(1):73-78.

45. Loprinzi CL, Kugler JW, Barton DL, et al. Phase III trial of gabapentin alone or in conjunction with an antidepressant in the management of hot flashes in women who have inadequate control with an antidepressant alone: NCCTG N03C5. J Clin Oncol. 2007;25(3):308-312.

46. [No authors listed]. Gabapentin extended-release - Depomed: Gabapentin ER, Gabapentin Gastric Retention, Gabapentin GR. Drugs R D. 2007;8(5):317-320.

47. Berner B, Cowles VE. Case studies in swelling polymeric gastric retentive tablets. Expert Opin Drug Deliv. 2006;3(4):541-548.

48. Cowles VE, Gordi T, Hou SY. Steady-state pharmacokinetics of gabapentin after administration of a novel gastroretentive extended-release formulation in postmenopausal women with vasomotor symptoms. Clin Drug Investig. 2012;32(9):593-601.

49. Chen C, Cowles VE, Hou E. Pharmacokinetics of gabapentin in a novel gastric-retentive extended-release formulation: comparison with an immediate-release formulation and effect of dose escalation and food. J Clin Pharmacol. 2011;51(3):346-358.

50. Stewart BH, Kugler AR, Thompson PR, Bockbrader HN. A saturable transport mechanism in the intestinal absorption of gabapentin is the underlying cause of the lack of proportionality between increasing dose and drug levels in plasma. Pharm Res. 1993;10(2): $276-281$. 
51. Meyer JH, Elashoff J, Porter-Fink V, Dressman J, Amidon GL. Human postprandial gastric emptying of 1-3 millimeter spheres. Gastroenterology. 1988;94(6):1315-1325.

52. Cowles VE, Gusler G, Chen TF, Hou SY, Wilding I, Berner B. Gastric emptying and intestinal transit of gastroretentive tablets in the fed state: effect of meal content and tablet size. Gastroenterology. 2004;126(Suppl 2):A489-A490.

53. Chien YW. Oral drug delivery and delivery systems. In: Novel Drug Delivery Systems, 2nd ed. New York, NY: Marcel Dekker;1992: 159-163.

54. Wallace MS, Irving G, Cowles VE. Gabapentin extended-release tablets for the treatment of patients with postherpetic neuralgia: a randomized, double-blind, placebo-controlled, multicentre study. Clin Drug Investig. 2010;30(11):765-776.

55. Sandercock D, Cramer M, Wu J, Chiang YK, Biton V, Heritier M. Gabapentin extended release for the treatment of painful diabetic peripheral neuropathy: efficacy and tolerability in a double-blind, randomized, controlled clinical trial. Diabetes Care. 2009;32(2):e20.
56. Irving G, Jensen M, Cramer M, et al. Efficacy and tolerability of gastricretentive gabapentin for the treatment of postherpetic neuralgia: results of a double-blind, randomized, placebo-controlled clinical trial. Clin J Pain. 2009;25(3):185-192.

57. Jensen MP, Chiang YK, Wu J. Assessment of pain quality in a clinical trial of gabapentin extended release for postherpetic neuralgia. Clin J Pain. 2009;25(4):286-292.

58. Bastien $\mathrm{CH}$, Vallières A, Morin CM. Validation of the Insomnia Severity Index as an outcome measure for insomnia research. Sleep Med. 2001;2:297-307.

59. Vernon MK, Brandenburg NA, Alvir JM, Griesing T, Revicki DA. Reliability, validity, and responsiveness of the daily sleep interference scale among diabetic peripheral neuropathy and postherpetic neuralgia patients. J Pain Symptom Manage. 2008;36(1):54-68.
International Journal of General Medicine

\section{Publish your work in this journal}

The International Journal of General Medicine is an international, peer-reviewed open-access journal that focuses on general and internal medicine, pathogenesis, epidemiology, diagnosis, monitoring and treatment protocols. The journal is characterized by the rapid reporting of reviews, original research and clinical studies across all disease areas.

\section{Dovepress}

A key focus is the elucidation of disease processes and management protocols resulting in improved outcomes for the patient.The manuscript management system is completely online and includes a very quick and fair peer-review system. Visit http://www.dovepress.com/ testimonials.php to read real quotes from published authors. 